\title{
Exclusive breast-feeding among children attending well-baby clinic at Al-Eskan PHC Center, Makkah Al-Mokarramah
}

\author{
Eman Al-Mohandis \\ Al-Zahir Primary Health Care Center, Ministry of Health, Makkah Al-Mokarramah, Saudi Arabia. \\ Correspondence to: Eman Al-Mohandis, E-mail: dr.eimi@hotmail.com \\ Received December 9, 2014. Accepted December 13, 2014
}

\section{Abstract}

Background: The World Health Organization (WHO), the American Academy of Pediatrics, and the US Preventive Services Task Force, all recommend exclusive breast-feeding for the first 6 months of life.

Objectives: To estimate the prevalence of exclusive breast-feeding and its associated factors among children attending well-baby clinic at Al-Eskan Primary Health Care (PHC) Center, Makkah Al-Mokarramah in August 2012.

Materials and Methods: A cross-sectional study was conducted including mothers attending well-baby clinic with their children at Al-Eskan PHC Center, Makkah Al-Mokarramah. A valid interviewing questionnaire was applied including demographic data of mothers (age, nationality, education, marital status, income, job, number of children, and age of the last child) and history of feeding of the index child and factors related to the exclusive breast-feeding.

Results: The study included 65 mothers aged between 19 and 44 years, with a mean of 28.6 years and standard deviation of 5.7 years. Of them, 49 mothers $(75.4 \%)$ initially breast-fed their infants. Only 12 of them (18.5\%) performed exclusive breast-feeding during the first 6 months after delivery. Among mothers who initiated breast-feeding after delivery $(n=49)$, $18(36.7 \%)$ stopped breast-feeding before the age of 6 months and $9(18.4 \%)$ stopped breast-feeding between the age of 6 months and 1 year whereas 22 mothers (44.9\%) continued breast-feeding. No statistical significant relationship was found between any of the studied parameters and the practice of exclusive breast-feeding. Slightly less than half of mothers $(46.2 \%)$ mentioned that exclusive breast milk is not enough in the first 6 months of child's life whereas $33.8 \%$ of them mentioned that it is enough.

Conclusion: Breast-feeding exclusivity among our sample is suboptimal, compared to the current WHO recommendations. Almost half of women reported that exclusive breast milk is not enough in the first 6 months of child's life.

KEY WORDS: Exclusive, breast-feeding, well-baby, prevalence

\section{Introduction}

Breast-feeding is the optimal feeding for all infants and its benefits for both infants and mothers are proven. The World Health Organization (WHO),${ }^{[1]}$ the American Academy of Pediatrics, ${ }^{[2]}$ and the US Preventive Services Task Force, ${ }^{[3]}$ all recommend exclusive breast-feeding for the first 6 months of life.

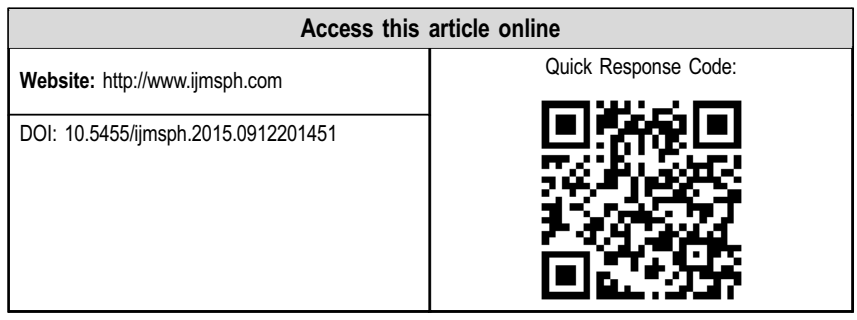

Recently, there has been increasing concern about the decline in breast-feeding pattern. A review of some statistics on breast-feeding in Saudi Arabia shows the single most common reason for introduction of bottle-feeding is breast milk is insufficient. ${ }^{[4]}$

A surveillance of infant feeding practices carried out in Riyadh city showed $98.9 \%$ of infants were started on breastfeeding after birth, and $52.7 \%, 30.8 \%$, and $18.8 \%$ continued on breast-feeding to 6,12 , and 18 months, respectively. ${ }^{[5]}$

In a Dutch population-based study, breast-feeding rate was $96 \%$ in the highest educated mothers and $73 \%$ in the lowest, ${ }^{[6]}$ and the Centers for Disease Control and Prevention (CDC) represented lower breast-feeding rate in younger mothers, black, below the poverty income ratio, with the lowest educational level, and lived in rural areas. ${ }^{[7]}$

Strong evidence showed that educational and support interventions improve breast-feeding rates. ${ }^{[8]}$ However, clinicians 
have a major contribution in increasing mothers' awareness of breast-feeding but counseling alone has not proven to be effective. ${ }^{[9]}$

This study aimed to estimate the prevalence of exclusive breast-feeding and its associated factors among children attending well-baby clinic at Al-Eskan Primary Health Care (PHC) Center, Makkah Al-Mokarramah, Saudi Arabia.

\section{Materials and Methods}

This is a cross-sectional analytic study based on children attending PHC center with their mothers. The study was conducted in Makkah Al-Mokarramah, Saudi Arabia. It is the holy capital city of the Kingdom of Saudi Arabia located in Makkah region at the west of the country. It has a plenty of health services as governmental and nongovernmental. There are seven government hospitals and $31 \mathrm{PHC}$ centers inside the city that provide free health-care services for all Saudi population; total population in Makkah in the last statistics at 2010 was around $1,675,368 .^{[10]}$ Al-Eskan is a main PHC Center in Makkah city and it is the training center for the researcher. Well-baby clinic is a vital clinic located opposite to vaccination room where mothers will arrive with their children. Total population covered by this center at 2011 was 15,376 .

Mothers attending well-baby clinic with their children at Al-Eskan PHC Center, Makkah Al-Mokarramah, constituted the study population. Using sample size online calculator (Raosoft), total population 200, expected prevalence according to nearest study to be $54 \%$ at sixth month, ${ }^{[11]}$ confidence level $95 \%$, and the margin of error $10 \%$, the estimated sample size was 65 . Using systematic random sampling technique, every third child was selected by systematic random sampling technique. First one was selected according to online random number.

A valid interviewing questionnaire was applied including demographic data of mothers (age, nationality, education, marital status, income, job, number of children, and age of the last child) and history of feeding of the index child and factors related to the exclusive breast-feeding.

The researcher conducted the pilot study on 10 mothers (out of the study) 1 month before data collecting, at Al-Eskan $\mathrm{PHC}$ Center to test the tool, the methodology, and the environment.

Approval of JPFCM, Makkah, was obtained. Permission of the Eskan PHC Center director was obtained. Verbal consent was obtained from all mothers.

Data were entered to a personal computer and were analyzed using Statistical Package for the Social sciences (SPSS 20) program, version 20. $\chi^{2}$-Test was applied to determine the association and/or difference between categorical variables. Student's $t$-test was applied to determine the difference in means of two quantitative variables (e.g., age and number of children). Fischer's exact test was applied whenever indicated (if the number of observations was less than 5 in at least one cell in contingency tables). A $p$-value of less than 0.05 was adopted for statistical significance.

\section{Results}

Table 1 presents the demographic characteristics of 65 mothers participated in the study. Their age ranged between 19 and 44 years with a mean of 28.6 years and standard deviation of 5.7 years. The majority of them (93.9\%) were at least secondary school graduated. All were Saudi nationals. All except one (98.5\%) were married. Their number of children ranged between 1 and 6 with a mean of $3.3 \pm 1.4$ children. Almost half of them (49.2\%) were housewives. Age of the last child was less than 6 months among $29.2 \%$ of them and between 6 months and less than 1 year among $32.3 \%$ of them. Their income was mostly (72.3\%) between 3,000 and 10,000 Saudi Riyal (SR)/month.

Table 1: Demographic characteristics of mothers attended well-baby clinic at Al-Eskan PHC center, Makkah Al-Mokarramah $(n=65)$

\begin{tabular}{|c|c|c|}
\hline Demographic characteristics & Frequency & Percentage \\
\hline \multicolumn{3}{|l|}{ Age (years) } \\
\hline Mean & 28.6 & \\
\hline Range & $19-44$ & \\
\hline$S D$ & 5.7 & \\
\hline \multicolumn{3}{|l|}{ Educational level } \\
\hline Primary & 1 & 1.5 \\
\hline Intermediate & 3 & 4.6 \\
\hline Secondary & 33 & 50.8 \\
\hline University & 28 & 43.1 \\
\hline \multicolumn{3}{|l|}{ Nationality } \\
\hline Saudi & 65 & 100.0 \\
\hline Non-Saudi & 0 & 0.0 \\
\hline \multicolumn{3}{|l|}{ Marital status } \\
\hline Married & 64 & 98.5 \\
\hline Divorced & 1 & 1.5 \\
\hline \multicolumn{3}{|l|}{ Number of children } \\
\hline Mean & 3.3 & \\
\hline Range & $1-6$ & \\
\hline SD & 1.4 & \\
\hline \multicolumn{3}{|l|}{ Job status } \\
\hline Housewife & 32 & 49.2 \\
\hline Student & 9 & 13.8 \\
\hline Employee & 24 & 37.0 \\
\hline \multicolumn{3}{|l|}{ Age of the last child } \\
\hline$<6$ months & 19 & 29.2 \\
\hline 6 months to $<1$ year & 21 & 32.3 \\
\hline 1 to 2 years & 20 & 30.8 \\
\hline$>2$ years & 5 & 7.7 \\
\hline \multicolumn{3}{|l|}{ Income (SR/month) } \\
\hline$<3,000$ & 1 & 1.5 \\
\hline $3,000-5,000$ & 21 & 32.3 \\
\hline $5,001-10,000$ & 26 & 40.0 \\
\hline$>10,000$ & 17 & 26.2 \\
\hline
\end{tabular}




\section{Breast-feeding History}

Forty-nine mothers $(75.4 \%)$ initially breast-fed their infants. Only 12 of them (18.5\%) performed exclusive breast-feeding during the first 6 months after delivery as shown in Figure 1.

Among mothers who initiated breast-feeding after delivery ( $n=49), 12$ only $(24.5 \%)$ completed exclusive breast-feeding during the first 6 months after delivery whereas $31(63.3 \%)$ added artificial milk and $5(10.2 \%)$ added water to breastfeeding during the first 6 months after delivery. Eighteen mothers $(36.7 \%)$ stopped breast-feeding before the age of 6 months and $9(18.4 \%)$ stopped breast-feeding between the age of 6 months and 1 year whereas 22 mothers (44.9\%) continued breast-feeding. Regarding frequency of breastfeeding per day among those who initiated breast-feeding,

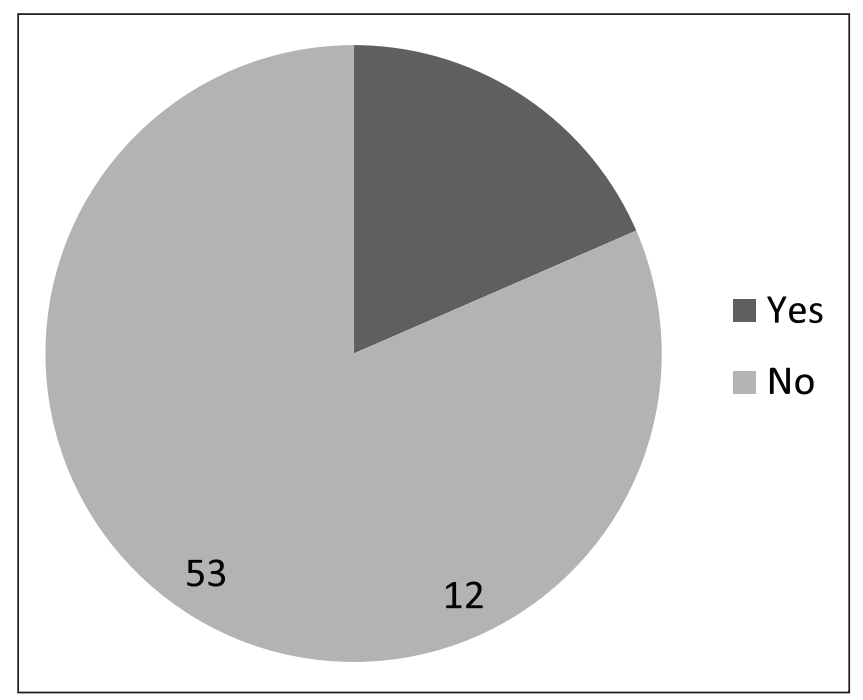

Figure 1: History of exclusive breast-feeding during the first 6 months after delivery $(n=65)$

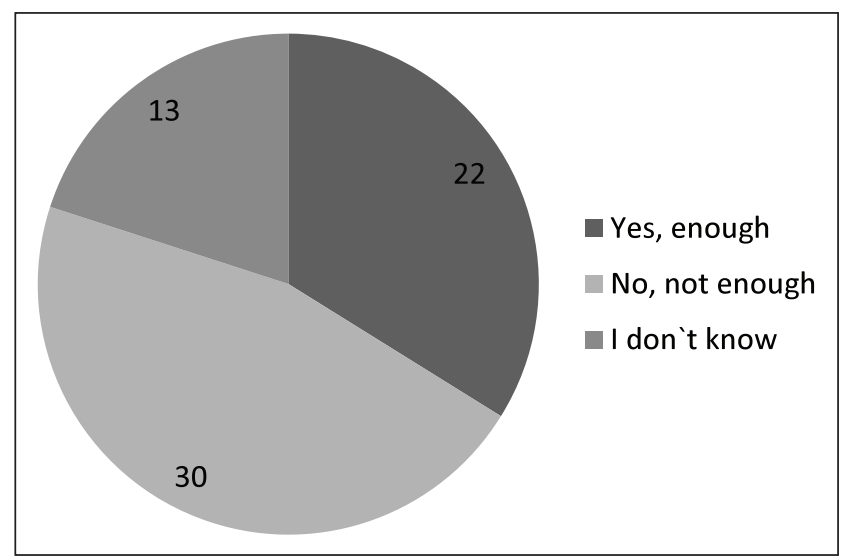

Figure 2: Attitude of mothers attended well-baby clinic at Al-Eskan PHC center toward exclusive breast-feeding

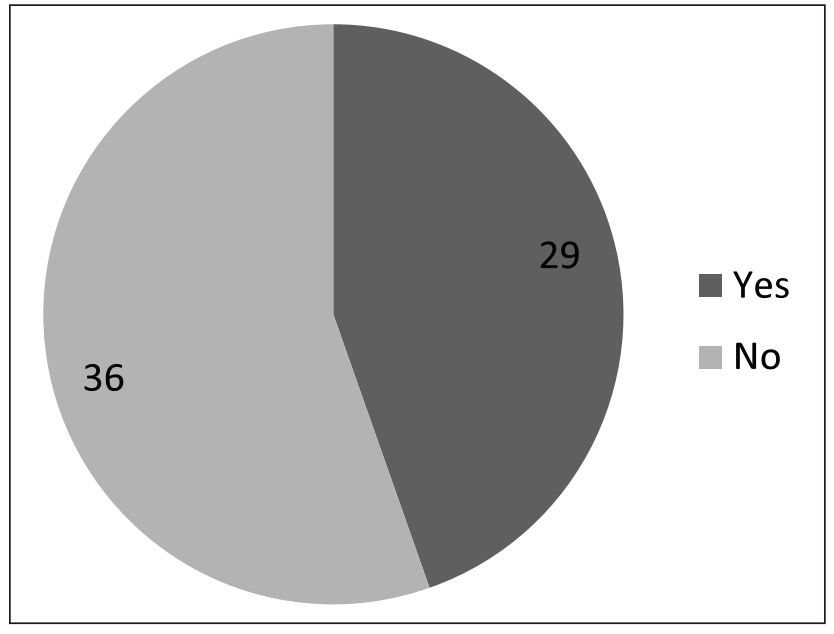

Figure 3: History of breast-feeding health education among mothers attended well-baby clinic at Al-Eskan PHC center, Makkah Al-Mokarramah $(n=65)$

$55.2 \%$ breast-fed their children on demand whereas $36.7 \%$ breast-fed them from five to nine times per day.

More than half of mothers (53.8\%) delivered their last child by cesarean delivery whereas $46.2 \%$ delivered normally. More than one-quarter of mothers $(26.2 \%)$ were current smokers, mostly moasil (16 of 17 smoker women). Regarding contraception history, more than half of mothers $(52.3 \%)$ reported contraception use. Among them, $70.6 \%$ used oral contraceptives whereas $29.4 \%$ used intrauterine device.

\section{Mothers' Attitude toward Exclusive Breast-feeding}

Figure 2 shows that slightly less than half of mothers $(46.2 \%)$ mentioned that exclusive breast milk is not enough in the first 6 months of child's life whereas $33.8 \%$ of them mentioned that it is enough.

\section{Breast-feeding Education}

Figure 3 shows that more than half of mothers $(55.4 \%)$ claimed that they had no health education regarding breastfeeding whereas $44.6 \%$ reported that they had such education. The source of this education was the well-baby clinic among almost two-thirds (65.5\%) of those reported history of health education. A booklet as a source of education was reported by $31 \%$ of them.

\section{Factors Associated with Initiation of Breast-feeding}

As shown in Table 2, the mean age of mothers who initiated breast-feeding after delivery was significantly higher than that of mothers who did not initiate breast-feeding after delivery $(29.8 \pm 5.4$ vs $25.1 \pm 5.2), p<0.01$. Mother's educational level, income, number of children, and job were not significantly associated with initiation of breast-feeding 
Table 2: Factors associated with initiation of breast-feeding after delivery

\begin{tabular}{|c|c|c|c|}
\hline & \multicolumn{2}{|c|}{ Initiating breast-feeding } & \multirow[t]{2}{*}{ P-value* } \\
\hline & Yes (N = 49), [N (\%)] & No $(N=16),[N(\%)]$ & \\
\hline Age (years) [mean (SD)] & $29.8(5.4)$ & $25.1(5.2)$ & $0.004^{\star *}$ \\
\hline \multicolumn{4}{|l|}{ Educational level } \\
\hline Secondary school or lower & $28(75.7)$ & $9(24.3)$ & \\
\hline Secondary school or higher & $21(75.0)$ & $7(25.0)$ & 0.950 \\
\hline$\leqslant 5,000$ & $16(72.7)$ & $6(27.3)$ & \\
\hline $5,001-10,000$ & $19(73.1)$ & $7(26.9)$ & \\
\hline$>10,000$ & $14(82.4)$ & $3(17.6)$ & 0.740 \\
\hline Number of children [mean (SD)] & $3.4(1.4)$ & $2.9(1.3)$ & $0.197^{\star *}$ \\
\hline \multicolumn{4}{|l|}{ Mother's job } \\
\hline Housewife & $27(84.4)$ & $5(15.6)$ & \\
\hline Student & $5(55.6)$ & $4(44.4)$ & \\
\hline \multicolumn{4}{|l|}{ Age of the last child } \\
\hline$<6$ months & $16(84.2)$ & $3(15.8)$ & \\
\hline 6 months to $<$ one year & $14(66.7)$ & $7(33.3)$ & \\
\hline 1 to 2 years & $14(70.0)$ & $6(30.0)$ & \\
\hline$>2$ years & $5(100.0)$ & $0(0.0)$ & 0.308 \\
\hline \multicolumn{4}{|l|}{ Mode of delivery } \\
\hline Normal & $23(76.7)$ & $7(23.3)$ & \\
\hline Cesarean delivery & $26(74.3)$ & $9(25.7)$ & 0.824 \\
\hline \multicolumn{4}{|l|}{ Maternal smoking } \\
\hline No & $36(75.0)$ & $12(25.0)$ & \\
\hline Yes & $13(76.5)$ & $4(23.5)$ & $0.592^{\circ}$ \\
\hline \multicolumn{4}{|l|}{ Contraception } \\
\hline No & $24(77.4)$ & $7(22.6)$ & \\
\hline Yes, oral contraceptives & $17(70.8)$ & $7(29.2)$ & \\
\hline No & $27(75.0)$ & $9(25.0)$ & \\
\hline Yes & $22(75.9)$ & $7(24.1)$ & 0.936 \\
\hline
\end{tabular}

IUD, intrauterine device.

${ }^{*} \chi^{2}$-Test; ${ }^{* *}$ t-test; ${ }^{\circ}$ Fischer's exact test.

after delivery. Other studied factors (age of the last child, mode of delivery, maternal smoking, contraceptive use, and history of health education) were not significantly associated with initiation of breast-feeding after delivery.

\section{Factors Associated with Exclusive \\ Breast-feeding}

As shown in Table 3, none of the studied variables was significantly associated with exclusive breast-feeding.

\section{Discussion}

It is highly desirable that breast-feeding is to be initiated soon after birth, preferably within the first 30 min of delivery. However, it is well documented that mothers in the Arabian countries, especially in the Gulf countries, start feeding their babies with prelacteal feeds and then ghee until the mother lactates. ${ }^{[12]}$

Currently the recommendations from the global strategy for infant and young child feeding, developed by the WHO and UNICEF, are that infants should be exclusively breast-fed for the first 6 months of life. ${ }^{[1]}$ Still, less than $40 \%$ of infants less than 6 months of age in the developing world are exclusively breast-fed. ${ }^{[13]}$ Despite the great advances in health services in Saudi Arabia, studies have reported a downward trend in breast-feeding practice. ${ }^{[6,11,14-16]}$ In this study, $75.4 \%$ of women initiated breast-feeding after delivery. However, only $18.5 \%$ were exclusively breast-fed. Much lower rates were reported from other regions of Saudi Arabia. In Riyadh, only $0.8 \%$ of infants were exclusively breast-fed for the first 4-6 months, ${ }^{[6]}$ and the rate rises to $1.7 \%$ among infants at the age 
Table 3: Factors associated with exclusive breast-feeding

\begin{tabular}{|c|c|c|c|}
\hline & \multicolumn{2}{|c|}{ Exclusive breast-feeding } & \multirow[t]{2}{*}{$P$-value* } \\
\hline & Yes $(N=12),[N(\%)]$ & No $(N=53),[N(\%)]$ & \\
\hline Age (years) [mean (SD)] & $29.4(6.2)$ & $28.5(5.7)$ & $0.602^{* *}$ \\
\hline \multicolumn{4}{|l|}{ Educational level } \\
\hline Secondary school or lower & $6(16.2)$ & $31(83.8)$ & \multirow[t]{2}{*}{0.592} \\
\hline Secondary school or higher & $6(21.4)$ & $22(78.6)$ & \\
\hline \multicolumn{4}{|l|}{ Income (SR/month) } \\
\hline$\leqslant 5,000$ & $5(22.7)$ & $17(77.3)$ & \multirow[t]{3}{*}{0.501} \\
\hline $5,001-10,000$ & $3(11.5)$ & $23(88.5)$ & \\
\hline$>10,000$ & $4(23.5)$ & $13(76.5)$ & \\
\hline Number of children [mean (SD)] & $3.3(1.6)$ & $3.3(1.3)$ & $0.843^{* *}$ \\
\hline \multicolumn{4}{|l|}{ Mother's job } \\
\hline Housewife & 7 (21.9) & $25(78.1)$ & \multirow[t]{3}{*}{0.638} \\
\hline Student & $2(22.2)$ & $7(77.8)$ & \\
\hline Employee & $3(12.5)$ & $21(87.5)$ & \\
\hline \multicolumn{4}{|l|}{ Age of the last child } \\
\hline$<6$ months & $3(15.8)$ & $16(84.2)$ & \multirow[t]{4}{*}{0.133} \\
\hline 6 months to $<1$ year & $7(33.3)$ & $14(66.7)$ & \\
\hline 1 to 2 years & $1(5.0)$ & $19(95.0)$ & \\
\hline$>2$ years & $1(20.0)$ & $4(80.0)$ & \\
\hline \multicolumn{4}{|l|}{ Mode of delivery } \\
\hline Normal & $7(23.3)$ & $23(76.7)$ & \multirow[t]{2}{*}{0.349} \\
\hline Cesarean delivery & $5(14.3)$ & $30(85.7)$ & \\
\hline \multicolumn{4}{|l|}{ Maternal smoking } \\
\hline No & $9(18.8)$ & $39(81.3)$ & \multirow[t]{2}{*}{$0.617^{\circ}$} \\
\hline Yes & $3(17.6)$ & $14(82.4)$ & \\
\hline \multicolumn{4}{|l|}{ Contraception } \\
\hline No & $7(22.6)$ & $24(77.4)$ & \multirow[t]{3}{*}{0.645} \\
\hline Yes, oral contraceptives & $4(16.7)$ & $20(83.3)$ & \\
\hline Yes, IUD & $1(10.0)$ & $9(90.0$ & \\
\hline \multicolumn{4}{|l|}{ Health education } \\
\hline No & $6(16.7)$ & $30(83.3)$ & \multirow[t]{2}{*}{0.678} \\
\hline Yes & $6(20.7)$ & $23(79.3)$ & \\
\hline
\end{tabular}

IUD, intrauterine device.

${ }^{*} \chi^{2}$-Test; ${ }^{* *} t$-test; ${ }^{\circ}$ Fischer's exact test.

of 6 months in Jeddah. ${ }^{[16]}$ Higher rates of $24.4 \%, 27.3 \%$, and $33.1 \%$ were reported in Al-Hassa, ${ }^{[17]}$ Al-Kharj, ${ }^{[15]}$ and Dammam, ${ }^{[18]}$ respectively. In Abha, KSA, Al-Binali ${ }^{[19]}$ reported that breast-feeding rate at 6 months among working mothers in Abha, was $15.9 \%$ and bottle-feeding was started, based on a provisional advice, in $56.7 \%$.

The rate of exclusive breast-feeding varies in Middle East countries. In Al-Ain, United Arab Emirates, only 4\% of mothers practiced exclusive breast-feeding during the first month of their infants' lives. ${ }^{[20]}$ In Iran, a recent study reported that $82 \%$ infants were exclusively breast-fed during the first month of life, but this statistic decreased to $44 \%$ and $2 \%$ at the ages of 4 and 6 months, respectively. ${ }^{[21]} \mathrm{A}$ more recent study in Iran reported rates of $56.8 \%$ and $27.7 \%$ at 4 and 6 months of age, respectively, at the national level. ${ }^{[22]}$ In Aqaba, Jordan, the exclusive breast-feeding rate was $46 \%$ for infants in the first 6 months of life. ${ }^{[23]}$ In Egypt, a rate of $42.5 \%$ was reported among infants less than 4 months of age. ${ }^{[24]}$ A study in Bangladesh reported an exclusive breast-feeding rate of $53 \%$ at 1 month and then a gradual decline to $5 \%$ at 6 months of age. ${ }^{[25]}$ A recent study in Bangladesh showed that this rate gradually declined from $87.1 \%$ at 1 month to $77.2 \%$ at 3 months and $61.4 \%$ at 6 months. ${ }^{[26]}$ In the United States, only $13.3 \%$ infants were exclusively breast-fed at 6 months of age. ${ }^{[27]}$ It has been commented that exclusive breastfeeding in the first 4 months of life varies from $1 \%$ to $90 \%$, depending on where the baby is born; this variability is influenced by cultural beliefs, socioeconomic status, ethnicity, education, urbanization, modernization, and local feeding practices. ${ }^{[28,29]}$

These figures as well as ours are low compared to those reported from the developed world; for example, at 4-6 months, in Luxembourg $54 \%$ of mothers exclusively breast-fed their newborns; in the Netherlands 37\%; and in Austria 46\%. ${ }^{[30]}$ 
It is documented that older mothers practiced exclusive breast-feeding more than younger mothers. ${ }^{[31]}$ However, a negative association existed between level of education of the mother and her family income with exclusive breast-feeding. ${ }^{[31,32]}$

In this study, the results obtained indicated no statistical significant relationship between any of the studied parameters and the practice of exclusive breast-feeding, most probably due to relative small sample size. In this study, older women more significantly tended to initiate breast-feeding than younger women.

In this study, employees were less likely to initiate and exclusively breast-fed their children than housewives. However, it was not a statistically significant determinant for nonpracticing exclusive breast-feeding, most probably due to our small sample size. Despite the fact that Saudi women do not work in hazardous occupations, a mother's work per se does adversely affect breast-feeding practice. Breast-feeding and working outside home are commonly believed to be incompatible activities, and maternal employment has long been considered a barrier to successful breast-feeding. ${ }^{[24]}$ Because of the short period of paid maternal leave (only 2 months) in Saudi Arabia, only $12.5 \%$ of employee mothers were able to exclusively breast-fed their infants till the age of 6 months. A negative effect of maternal work on exclusive breast-feeding has been reported by many studies in different cultures. ${ }^{[3-36]}$ However, other studies in accordance with the results of our study have reported no effect of maternal work on exclusive breast-feeding. $^{[37,38]}$

Furthermore, in developing countries demonstrating population transition with increasing urbanization, women achieving higher levels of formal education and more working outside of their households are expected to witness a decrease in the practice and duration of breast-feeding across time ${ }^{[39,40]}$ a scenario that is applicable to the Saudi Arabian community where women account for $55 \%$ of university graduates and the urban population represents $82 \%$ of the total with a rate of urbanization equals to $2.5 \%$ annual rate of change (for 2005-2010) and ranked 39th in the global rank of urbanization in the year $2009 .{ }^{[41]}$ In this study, university graduated mothers approaching $43 \%$.

This study includes only mothers attending for vaccination at PHC centers in one region of the Saudi Arabia, and the results may not be representative of the whole nation. In addition, the study findings merely convey associations rather than inferences because of the study design adopted; a prospective cohort design would be more appropriate.

\section{Conclusion}

In conclusion, breast-feeding exclusivity among our sample is suboptimal, compared to the current WHO recommendations. Implementation of evidence-based health promotion and education programs relating to breast-feeding required for the future parents as well as for adolescent school students for the enhancement of positive breast-feeding attitudes is recommended.

\section{References}

1. World Health Organization. The Global Strategy for Infant and Young Child Feeding. Geneva: WHO, 2003. Available at: www.who.int/nutrition/publication/index.html (last accessed on February 9, 2003).

2. Gartner LM, Morton J, Lawrence RA, Naylor AJ, O'Hare D, Schanler RJ, et al. Breastfeeding and the use of human milk. Pediatrics 2005;115(2):496-506.

3. US Preventive Services Task Force. Primary care interventions to promote breastfeeding: U.S. Preventive Services Task Force recommendation statement. Ann Intern Med 2008;149:560-4.

4. Al-Jassir M, Moizuddin SK, Al-Bashir B. A review of some statistics on breastfeeding in Saudi Arabia. Nutr Health 2003; 17(2):123-30

5. Al-Jassir MS, El-Bashir BM, Moizuddin SK. Surveillance of infant feeding practices in Riyadh city. Ann Saudi Med 2004;24(2):136-40.

6. van RL, Oenema A, Steegers EA, Moll HA, Jaddoe VW, Hofman $A$, et al. Are starting and continuing breastfeeding related to educational background? The generation $\mathrm{R}$ study. Pediatrics 2009;123(6):e1017-27.

7. CDC. Recommendation for Breastfeeding. Available at: www.cdc. gov/breasfeeding/data/NIS_data/index.html (last accessed on June 21, 2009).

8. Chung M, Raman G, Trikalinos T, Lau J, Ip S. Interventions in primary care to promote breastfeeding: an evidence review for the U.S. Preventive Services Task Force. Ann Intern Med 2008; 149(8):565-82.

9. Guise JM, Palda V, Westhoff C, Chan BK, Helfand M, Lieu TA, et al. The effectiveness of primary care-based interventions to promote breastfeeding: systematic evidence review and meta-analysis for the US Preventive Services Task Force. Ann Fam Med 2003;1(2):70-8.

10. Saudi Arabia Ministry of Health. Annual Population Census, 2010. Available at: www.moh.gov.sa/statistics/indi_phc.html (last accessed on January 8,2011 ).

11. Shawky S, Abalkhail BA. Maternal factors associated with the duration of breast feeding in Jeddah, Saudi Arabia. Paediatr Perinat Epidemiol 2003;17(1):91-6.

12. Sawaya WR, Al-Othaimeen TA, Khalil J. Breast-feeding practice in Saudi Arabia. Food Nutr Bull 1987;9(2):62-8.

13. UNICEF. Maternal and Newborn Health. The State of the World's Children 2009. www.unicef.org/sowc08/docs/sowc09-FullReportEN.pdf (last accessed on September 2010).

14. Al-Shehri SN, Farag MK, Baldo MH, Al-Mazrou YY, Aziz KM. Overview on breastfeeding pattern in Saudi Arabia J Trop Pediatr 1995;41(Suppl 1):S38-44.

15. Ogbiede DO, Siddiqui S, Al-Khalifa IM, Karim A. Breastfeeding in a Saudi Arabian community: Profile of parents and influencing factors. Saudi Med J 2004;25:580-4.

16. Al-Hreashy FA, Tamim HM, Al-Baz N, Al-Kharji NH, Al-Amer A, Al-Ajmi $\mathrm{H}$, et al. Patterns of breastfeeding practice during the first 6 months of life in Saudi Arabia. Saudi Med J 2008;29:427-31.

17. El-Gilany A, Shady E, Helal R. Exclusive breastfeeding in Al-Hassa, Saudi Arabia. Breastfeed Med 2011;6(4):209-13.

18. Qadri MH, Al-Harfi RA, Al-Gamdi MA. Breastfeeding practice in Dammam area of Saudi Arabia. J Family Community Med 1998:5:59-64.

19. Al-Binali AM. Knowledge, attitude and practice of breastfeeding among female health care workers in tertiary care hospitals. Med J Cairo Univ 2011;79(4):361-7. 
20. Al-Mazroui MJ, Oyejide CO, Bener A, Cheema MY. Breastfeeding and supplemental feeding for neonates in Al-Ain, United Arab Emirates. J Trop Pediatr 1997;43:304-6.

21. Koosha A, Hashemifesharaki R, Mousavinasab N. Breastfeeding patterns and factors determining exclusive breastfeeding. Singapore Med J 2008;49:1002-6.

22. Olang B, Farivar K, Heidarzadeh A, Strandvik B, Yngve A. Breastfeeding in Iran: prevalence, duration and current recommendations. Int Breastfeed J 2009;4:8.

23. Amayreh W, Ghanma A, Al-Jbour W, Zayadeen K. Factors affecting infant feeding practices at Aqaba, South of Jordan. Middle East J Nurs 2007;1:12-13.

24. El-Gilany A. Breastfeeding indicators in Dakahlia governorate. East Mediterr Health J 2003;9:961-73.

25. Arifeen S, Black RE, Antelman G, Baqui A, Caulfield L, Becker S, et al. Exclusive breastfeeding reduces acute respiratory infection and diarrhea deaths among infants in Dhaka slums. Pediatrics 2001;108:e67.

26. Mihrshahi S, Oddy WH, Peat JK, Kabir I. Association between infant feeding patterns and diarrheal, respiratory illness: A cohort study in Chittagong, Bangladesh. Int Breastfeed J 2008;3:28.

27. Li R, Darling N, Maurice E, Barker L, Grummer-Strawn LM. Breastfeeding rates in the United States by characteristics of the child, mother, or family: the $\mathbf{2 0 0 0}$ National Immunization Survey. Pediatrics 2005;115:e31-7.

28. UNICEF. Progress for Children: A Child Survival Report Card, 2004. Available at: www.unicef.org/publications/files/29652L01. engpdf (last accessed on September 2010).

29. Ergenekon-Ozelci P, Elmaci N, Ertem M, Saka G. Breastfeeding beliefs and practices among migrant mothers in slums in Diyarbakir, Turkey, 2001. Eur J Public Health 2006;16:143-8.

30. Yngve A, Sjostrom M. Breastfeeding in countries of the European Union and EFTA: current and proposed recommendations, rationale, prevalence, duration and trends. Public Health Nutr 2001;4:631-45.

31. Al-Shoshan AA. Factors affecting mother's choices and decisions related to breast feeding practices and weaning habits. Pak J Nutr 2007;6(4):318-22.
32. Al-Frayh A. Current trends in infant feeding in Saudi society. J Obs Gyn 1989;10:521-2.

33. Khassawneh M, Khader Y, Amarin Z, Alkafajei A. Knowledge, attitude and practice of breastfeeding in the north of Jordan: a cross-sectional study. Int Breastfeed J 2006;1:17.

34. El-Gilany A, El-Wehady A. Maternal work and infant health in Al-Hassa, Saudi Arabia. Paediatrics Me 2007;12(4):100-5.

35. Tan KL. Factors associated with non-exclusive breastfeeding among 4-week post-partum mothers in Klang District, Peninsular Malaysia. Malays J Nutr 2009;15:11-18.

36. Al-Sahab B, Lanes A, Feldman M, Tamim H. Prevalence and predictors of 6-months exclusive breastfeeding among Canadian women: a national survey. BMC Pediatr 2010;10:20.

37. Chudasama RK, Amin CD, Parikh YN. Prevalence of exclusive breastfeeding and its determinants in first 6 months of life: a prospective study. Online J Health Allied Sci 2009;8(1).

38. Petrova A, Ayers C, Stechna S, Gerling JA, Mehta R. Effectiveness of exclusive breastfeeding promotion in low-income mothers: a randomized controlled study. Breastfeed Med 2009; 4:63-9.

39. Pérez-Escamilla R. Breastfeeding and the nutritional transition in the Latin American and Caribbean Region: a success story? Cad Saude Publica, 2003;19(Suppl 1):S119-27.

40. Monteiro CA, Conde WL, Popkin BM. Independent effects of income and education on the risk of obesity in the Brazilian adult population. J Nutr 2001;131:881S-6S.

41. Central Intelligence Agency. The World Factbook. Available at: www.cia.gov/library/publications/theworldfactbook/fields/2212.html (last accessed on June 15, 2010).

How to cite this article: Al-Mohandis E. Exclusive breast-feeding among children attending well-baby clinic at Al-Eskan PHC Center, Makkah Al-Mokarramah. Int J Med Sci Public Health 2015;4: 279-285

Source of Support: Nil, Conflict of Interest: None declared. 